\title{
Inhibition of cell migration and invasion by miR-29a-3p in a colorectal cancer cell line through suppression of CDC42BPA mRNA expression
}

\author{
PEI YUAN HE ${ }^{1,2}$, WAI KIEN YIP ${ }^{1}$, BOON LEE CHAI ${ }^{1}$, BOON YEAN CHAI $^{1}$, MOHD FAISAL JABAR $^{3}$, \\ NORAINI DUSA ${ }^{4}$, NORHAFIZAH MOHTARRUDIN ${ }^{1}$ and HENG FONG SEOW ${ }^{1}$ \\ ${ }^{1}$ Department of Pathology, Faculty of Medicine and Health Sciences, Universiti Putra Malaysia, Serdang, Malaysia; \\ ${ }^{2}$ Department of Gastroenterology, Affiliated Hospital of Chengde Medical University, Chengde, Hebei, P.R. China; \\ ${ }^{3}$ Department of Surgery, Faculty of Medicine and Health Sciences, Universiti Putra Malaysia, \\ Serdang; ${ }^{4}$ Department of Pathology, Hospital Kuala Lumpur, Malaysia
}

Received March 3, 2017; Accepted August 9, 2017

DOI: $10.3892 /$ or.2017.6037

\begin{abstract}
The objective of this study was to determine the effect of miR-29a-3p inhibitor on the migration and invasion of colorectal cancer cell lines (CRC) and the underlying molecular mechanisms. miR-29a-3p was detected using reverse transcription-quantitative polymerase chain reaction (RT-qPCR) in the CRC cell lines HCT11, CaCo2, HT29, SW480 and SW620. An invasive subpopulation designated SW480-7 was derived from the parental cell line, detected by Transwell and Transwell Matrigel assays. Cytoskeleton Regulators $\mathrm{RT}^{2}$ profiler PCR array and western blot analysis were utilized to identify the alterations in expression of downstream mRNAs. siRNA against CDC42BPA was transfected into SW480-7 and effects on cell migration and invasion were investigated. Data obtained showed that miR-29a-3p was detected in these five CRC cell lines. miR-29a-3p inhibitor had no effect on viability but stimulated cell migration and invasion of SW480-7 cells. In contrast, miR-29a-3p mimic suppressed cell migration and invasion. TargetScan miRBD and DIANA were employed to identify the potential direct target genes of miR-29a-3p in the Cytoskeleton Regulators RT2²-Profiler PCR array. Cytoskeleton Regulators $\mathrm{RT}^{2}$-Profiler PCR array data showed that 3 out of the 5 predicted targets genes, CDC42BPA (2.33-fold), BAIAP2 (1.79-fold) and TIAM1 (1.77-fold), in the array were upregulated by miR-29a-3p. A significant increase in expression IQGAP2, PHLDB2, SSH1 mRNAs and downregulation of PAK1 mRNA was also detected with miR-29a-3p inhibition. Increase in CDC42BPA, SSH1 and
\end{abstract}

Correspondence to: Professor Heng Fong Seow, Department of Pathology, Faculty of Medicine and Health Sciences, Universiti Putra Malaysia, Serdang, Selangor 43400, Malaysia

E-mail: shf@upm.edu.my

Key words: miR-29a-3p, CDC42BPA, migration, invasion, colorectal cancer, cytoskeleton
IQGAP2 mRNA expression correlated with increased protein level in miR-29a-3p transfected SW-480-7 cells. Silencing of CDC42BPA (an enhancer of cell motility) partially abolished miR-29a-3p inhibitor-induced stimulation of cell migration and invasion. miR-29a-3p expression in stage II and III CRC is relatively lower than that of stage ICRC. However, the data need to be interpreted with caution due to the small sample size. In conclusion, inhibition of miR-29a-3p stimulates SW480-7 cell migration and invasion and downstream expression IQGAP2, PHLDB2, SSH1 mRNAs are upregulated whilst PAK1 mRNA is downregulated. Silencing of CDC42BPA expression partially reduces miR29a-3p inhibitor-induced migration and invasion of SW480-7 cells.

\section{Introduction}

Cancer is a set of diseases characterized by limitless replication and activation of metastasis. Colorectal cancer (CRC) is the second and third most common malignancy in females and males, respectively (1). The major cause of death in patients with CRC is the development of metastasis. Despite considerable advances in the detection and treatment of colorectal cancer, majority of patients are diagnosed at advanced stages when treatment is difficult and most of these patients will die within 5 years. Further investigation of CRC tumorigenesis at a molecular level is required to develop effective agents or therapeutic approaches, particularly for recurrent and metastatic patients.

miRNAs are endogenous, small noncoding RNAs of 18-22 nucleotides long, and have emerged as important regulators of gene expression at post-transcriptional level (2). Deregulation of miRs is associated with several diseases including cancer. Accumulating studies have demonstrated that miRNAs play a vital role in diverse cellular processes implicated in cancer progression (3), such as cell migration (4), invasion (5), proliferation (6), apoptosis (7), and cell cycle regulation (8). These cellular processes have been shown to involve miR-29 which supports their role as effective regulators of tumorigenesis and cancer progression $(9,10)$. 
Tumor-associated miRs can function either as tumor suppressors or oncogenes depending on their target mRNAs $(11,12)$. Downregulation of miR-29a-3p has been reported in various types of cancers including gastric cancer (13), glioma (14), oral squamous cell carcinoma (15), cervical squamous cell carcinoma (16), hepatocellular carcinoma (17) and non-small cell lung cancer $(18,19)$ suggesting that miR-29 may potentially serve as a tumor suppressor.

By contrast, miR-29 overexpression has been reported in acute myeloid leukemia (20), B cell chronic lymphocytic leukemia (21), breast cancer (22) and colorectal cancer $(3,23,24)$. Plasma miR-29a can also be applied to the early detection of CRC metastasis (25) implying that they may potentially act as oncogenes. A previous study revealed that miR-29a-3p level was higher in both serum and tissue of CRC patients with liver metastases than that in patients without metastasis, indicating that miR-29a-3p might be involved in CRC progression (7). Kuo et al found that miR-29a can be used as a predictor of the early recurrence (26) and a risk marker for recurrence in stage II colon cancer (27). Thus, miR-29 can serve as a useful diagnostic and prognostic marker (28) and their tumor suppressive or oncogenic role is dependent on the cell type and tumor microenvironment.

Since miR-29a-3p expression is elevated in metastatic colorectal cancer, we hypothesized that inhibiting the expression of miR-29a-3p will block migration and invasion of colorectal cancer cells.

\section{Materials and methods}

Cell culture and transfection. All five colorectal cancer cell lines, SW620, SW480, HCT116, HT-29 and Caco2, were obtained from the American Type Culture Collection (Manassas, VA, USA) and maintained in complete RPMI-1640 medium supplemented with $10 \%$ fetal bovine serum (FBS), penicillin $(100 \mathrm{U} / \mathrm{ml})$, streptomycin $(100 \mu \mathrm{g} / \mathrm{ml})$, and $2 \mathrm{~g} / 1$ sodium bicarbonate (Gibco, Invitrogen Corp., Carlsbad, CA, $\mathrm{USA}$ ) at $37^{\circ} \mathrm{C}$ in humidified air with $5 \% \mathrm{CO}_{2}$.

miR-29a-3p inhibitor, miRNA inhibitor negative control (NC) oligos, miR-29a-3p mimic, miRNA mimic negative control (NC) oligos, were purchased from Exiqon (Vedbaek, Denmark). HCT116 and SW620 at a density of $5.3 \times 10^{4}$ and $1.3 \times 10^{5}$ cells $/ \mathrm{ml}$, respectively, were transfected with Lipofectamine 2000 (Invitrogen), and SW480 cells at a density of $1.1 \times 10^{4}$ cells $/ \mathrm{ml}$ were transfected with HiPerFect (Qiagen, Hilden, Germany) in 24-well plates according to the manufacturer's instructions. This was followed by MTT assay.

Patient samples. Archived paraffin-embedded CRC tissues and matched normal adjacent tissues were from 28 histologically confirmed CRC patients who underwent surgery in Kuala Lumpur Hospital between 2010 and 2011. Medical ethics was approved by the National Medical Research and Ethics Committee (NMRR-12-435-11565), and each patient provided consent to use their paraffin-embedded tissues. The tumors were staged according to the TNM staging system. All cases were reviewed and confirmed by two experienced pathologists. The clinical and pathological characteristics of patients are shown in Table I. Due to time and financial constraints, experiments were conducted with a small cohort containing 28 samples. Sections of $4-\mu \mathrm{m}$ thickness were cut and mounted on glass slides followed by deparaffinization and macrodissection under a microscope. The tumor area and normal adjacent colonic mucosae were scrapped off with a pipette tip and collected in $1.5 \mathrm{ml}$ microcentrifuge tubes.

$R T$ - $q P C R$ for miRNA detection. For assessment of miR-29a-3p expression in CRC tissues and colorectal cancer cell lines, total RNA including miRNA was purified using miRNeasy FFPE kit (Qiagen) and miRNeasy Micro kit (Qiagen) according to the manufacturer's instructions, respectively. U6 snRNA was employed as the endogenous reference gene for relative quantification of miRNA using RT-qPCR. Reverse transcription was conducted using the Universal cDNA synthesis kit (Exiqon) according to the manufacturer's instructions.

miR-29a-3p (cat. no. 204698) and U6 (cat. no. 203907) primers were purchased from Exiqon. As Locked Nucleic Acids Technology is covered by the patents owned by Exiqon, the sequences of the primers were not provided by the manufacturer. PCR was performed with a Mastercycler EP realplex 4 (Eppendorf, Germany) using $\mathrm{SYBR}^{\circledR}$ Green Master Mix Universal RT kit (Exiqon). PCR parameters were set as follows: polymerase activation at $95^{\circ} \mathrm{C}$ for $10 \mathrm{~min}, 40$ amplification cycles of denaturation at $95^{\circ} \mathrm{C}$ for $10 \mathrm{sec}$, annealing and extension at $60^{\circ} \mathrm{C}$ for $1 \mathrm{~min}$. Melting curve analysis was used to assess amplification specificity. Each sample was run in triplicate and each experiment was repeated for three times. Standard curve method was used to calculate the relative expression of miRNA (17).

MTT assay. To determine the effect of miR-29a-3p inhibitor on cell growth, MTT assay was used to assess cell viability following cell transfection with miR-29a-3p inhibitor. Cells were plated in 96-well plates in triplicates. After incubating the plate at $37^{\circ} \mathrm{C}$ for $24 \mathrm{~h}$, miRNA inhibitors were introduced into the cells via transfection. MTT reagent $(9 \mu \mathrm{l})$ at a concentration of $5 \mathrm{mg} / \mathrm{ml}$ was pipetted into each well after $96 \mathrm{~h}$ followed by incubation in cell culture incubator for $4 \mathrm{~h}$. The culture medium was then removed and $100 \mu 1$ DMSO was added into each well to dissolve intracellular formazan. The absorbance of each well was measured at $570 \mathrm{~nm}$ utilizing a spectrophotometric microtiter plate reader (Dynex Technologies, Inc., Chantilly, VA, USA). Negative control was regarded as calibrator and the absorbance was defined as $100 \%$. Relative viability of experimental cells was calculated by dividing the absorbance of experimental cells by that of negative control. Three independent experiments were performed for each treatment.

Transwell assay for cell migration and invasion. Transwell assay system was used to assess cell migration and cell invasion in the present study. Transwell migration assay is always performed with commercially available plastic inserts compatible with multiwell plates. The bottom of plastic insert is made up of microporous membrane allowing migratory cells to reach the other side of the membrane. To determine cell invasion, a gel containing similar components with basement membrane is formed on the microporous membrane. The only difference between migration assay and invasion assay is the presence of the basement membrane-like gel. Matrigel ${ }^{\mathrm{TM}}$ was added on the microporous membrane. Unbound Matrigel 
Table I. Clinical and pathological characteristics of patients included in this study.

\begin{tabular}{lc}
\hline $\begin{array}{l}\text { Clinicopathological } \\
\text { parameters }\end{array}$ & $\begin{array}{c}\text { No. of patients } \\
(\mathrm{n}=28)\end{array}$ \\
\hline Sex & 18 \\
Male & 10 \\
Female & \\
Age at diagnosis (years) & 5 \\
$\leq 60$ & 23 \\
$>60$ & \\
Race & 16 \\
Chinese & 10 \\
Malay & 2 \\
Indian & \\
Stage at diagnosis & 10 \\
I & 9 \\
II & 9 \\
III & \\
Tumor site & \\
Left & \\
Right & \\
Rectum & 5 \\
\hline
\end{tabular}

was aspirated and the plate was placed in an incubator at $37^{\circ} \mathrm{C}$ for $30 \mathrm{~min}$ to allow gelling. The membrane was coated twice with Matrigel. SW480-7 cells transfected with $10 \mathrm{nM}$ miRNA inhibitor or miRNA mimic for $48 \mathrm{~h}$ were detached with trypsin $(0.25 \%)$. Cells $\left(1.0 \times 10^{5}\right)$ resuspended in $200 \mu \mathrm{l}$ serum-free medium were pipetted into upper chamber, and $700 \mu \mathrm{l}$ medium with $10 \%$ FBS was added into lower chamber. After $72 \mathrm{~h}$ of incubation at $37^{\circ} \mathrm{C}$, the insert was soaked in ice-cold $95 \%$ ethanol for $10 \mathrm{~min}$ to fix the cells. The invaded cells and non-invaded cells were stained by propidium iodide (PI) and 4', 6-diamidino-2-phenylindole (DAPI), respectively. Cell counting of invaded and non-invaded cells was done using the Image-Pro Plus 6.0 software. The invasive capacity was represented by relative invasion that was determined using the formula: number of invaded cells stained by PI/number of non-invaded cells stained by DAPI. Three independent experiments were conducted to verify the reproducibility. The invasive capacity of a treated sample was normalized to that of corresponding control. One-sample t-test was used to test the differences of normalized invasive capacities of three independent experiments with the hypothetical value (set to 1).

$R T^{2}$ Profiler PCR array. SW480-7 cells were transfected with miR-29a-3p inhibitor or miRNA negative control oligos $48 \mathrm{~h}$ before the PCR array. Total RNA purification was conducted with GeneJET RNA Purification kit (cat. no. K0731; Thermo Scientific, USA). The integrity of extracted RNA was tested by agarose gel electrophoresis. Purity and quantity of RNA were determined using a Nandrop 1000 spectrophoto-
Table II. Sequences of primers used in qPCR analysis.

\begin{tabular}{ll}
\hline Gene & \multicolumn{2}{c}{ Primer } \\
\hline CDC42BPA & F: 5'-GCTGGTGGAGACATACGGAA-3' \\
& R: 5'-ACCAAGTCGATGTTCTCTGCT-3' \\
PHLDB2 & F: 5'-CCAGGGAACGGGAAATGGAA-3' \\
& R: 5'-GGTAGCGTGTCAAAGGACGA-3' \\
IQGAP2 & F: 5'-GCACACACTCACTCCTGTTG-3' \\
& R: 5'-GTCAACTGCTCCTTCCCCAA-3' \\
SSH1 & F: 5'-AAGAGACCACAGACCTCCTCG-3' \\
& R: 5'-GCGACTCACGCCCATTTTG-3' \\
PAK1 & F: 5'-GCATAGTGAGTGTGGGCGAT-3' \\
& R: 5'-CCCACGAGGTAACTGTCCAA-3' \\
GAPDH & F: 5'-AATCCCATCACCATCTTCCA-3' \\
& R: 5'-TGGACTCCACGACGTACTCA-3'
\end{tabular}

F, forward. R, reverse.

meter, and only RNA samples with A260: A280 absorbance values between 1.8 and 2.1 were used in subsequent experiments. Reverse transcription (RT) was performed with $\mathrm{RT}^{2}$ First Strand kit (cat. no. 330401; Qiagen) according to the manufacturer's protocol. Cytoskeleton Regulators RT ${ }^{2}$ Profiler PCR array plate (cat. no. PAHS-088ZA; Qiagen) was used to perform real-time quantitative PCR. Twenty-five microliters of PCR components mix was added to each well of the 96-well $\mathrm{RT}^{2}$ Profiler PCR array plate. Then, the plate was placed in the real-time cycler (Eppendorf, Wesseling-Berzdorf, Germany), and the PCR cycling program was set as follows: polymerase activation at $95^{\circ} \mathrm{C}$ for $10 \mathrm{~min}, 40$ amplification cycles of denaturation at $95^{\circ} \mathrm{C}$ for $15 \mathrm{sec}$, annealing and extension at $60^{\circ} \mathrm{C}$ for $1 \mathrm{~min}$.

$R T$-qPCR for mRNA confirmation. Total RNA purification was conducted with GeneJET RNA Purification kit (Thermo Scientific). cDNA was synthesized by ReverAid Reverse transcriptase at $42^{\circ}$ for $60 \mathrm{~min}$. Real-time PCR was performed with SYBR Select Master Mix (cat. no. 4472908, Life Technologies, CA, USA). Glyceraldehyde-3-phosphate dehydrogenase (GAPDH) was set as reference gene and the primer sequences are shown in Table II. Real-time PCR was conducted with a $10-\mu 1$ total volume, containing $1 \mu \mathrm{l}$ of cDNA template, $5 \mu 12 \mathrm{X} \mathrm{SYBR}{ }^{\circledR}$ Select Master Mix, $0.25 \mu 1$ forward/reverse primer, and 3.5 $\mu$ l of RNase-free water. PCR was performed on a Mastercycler EP realplex 4 (Eppendorf, Germany). The thermal cycler was programmed as follows: initial denaturation at $95^{\circ} \mathrm{C}$ for $2 \mathrm{~min}, 40$ cycles consisting of $95^{\circ} \mathrm{C}$ for $15 \mathrm{sec}, 60^{\circ} \mathrm{C}$ for $15 \mathrm{sec}, 72^{\circ} \mathrm{C}$ for $1.5 \mathrm{~min}$, and extension at $72^{\circ} \mathrm{C}$ for $10 \mathrm{~min}$. Standard curve method was used to calculate the relative expression of mRNA.

Western blot analysis. Total proteins were harvested from SW480-7 cells $72 \mathrm{~h}$ post-transfection with $300 \mu \mathrm{l}$ of $1 \mathrm{X}$ sodium dodecyl sulfate (SDS) lysis buffer. Approximately $20 \mu \mathrm{g}$ of 

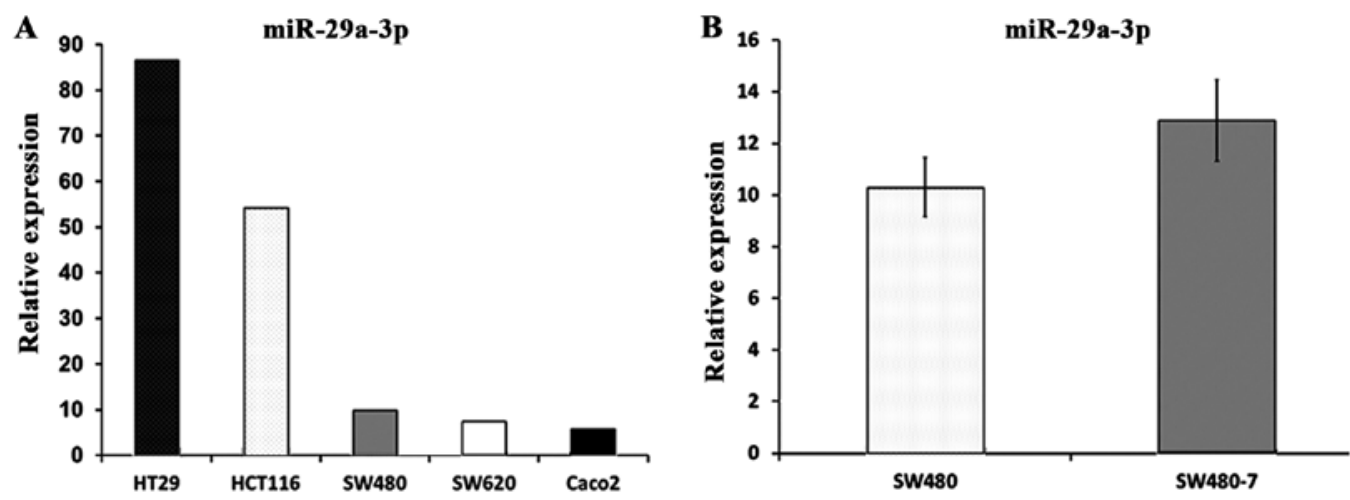

Figure 1. Expression of miR-29a-3p in five colorectal cancer cell lines. (A) Expression of miR-29a-3p in the cell lines, HCT116, Caco2, HT29, SW480 and SW620. (B) miR-29a-3p expression in SW480 and SW480-7 cells. Data represent the means \pm SD which were calculated from data of three independent experiments. U6 was used as endogenous reference gene.

protein samples were loaded on and electrophoresed in polyacrylamide gel electrophoresis (PAGE) in running buffer at $120 \mathrm{~V}$. The proteins in the gel were electrotransferred to a polyvinylidene fluoride (PVDF) membrane (Pierce, Thermo Fisher Scientific) in transfer buffer at $100 \mathrm{~V}$. After $2 \mathrm{~h}$ of transfer, the membrane was incubated in a blocking buffer (Tris-buffered saline containing $5 \%$ bovine serum albumin) at room temperature for $1 \mathrm{~h}$ with agitation. After blocking, the membrane was incubated with the corresponding primary antibody diluent $(1: 2,000)$ overnight at $4^{\circ} \mathrm{C}$. Then, the membrane was incubated with the species specific horseradish peroxidase conjugated secondary antibody (1:10,000 dilution; Cell Signaling Technology, USA) for $1 \mathrm{~h}$ at room temperature. The membrane was incubated with chemiluminescent substrate for $5 \mathrm{~min}$. After that, the membrane was visualized and the images were captured using a camera in the FluorChem ${ }^{\mathrm{TM}} 5500$ imaging system (Alpha Innotech Corp., San Leandro, CA, USA). Densitometric analysis was performed to evaluate band intensities using Image J software (National Institutes of Health, Bethesda, MD, USA). The values of targeted band density were normalized to those of $\alpha$-tubulin obtained from the same membrane. Three independent experiments were conducted.

Statistical analysis. Data obtained from the Cytoskeleton Regulators $\mathrm{RT}^{2}$ Profiler PCR array was analyzed by PCR Array Data Analysis Web Portal (www.SABiosciences.com/ pcrarraydataanalysis.php.) using the $\Delta \Delta \mathrm{Ct}$ method.

Data obtained in the RT-qPCR, viability, migration, invasion, and western blot assays was analyzed using one-sample t-test by GraphPad InStat version 3.05 for windows (GraphPad Software, Inc., San Diego, CA, USA). Moreover, paired t-test was used to statistically matched tissues, and one-way analysis was used to compare means of three stages in CRC tissues. Quantitative results were expressed as the mean \pm standard deviation. A two-sided P-value $<0.05$ was set as the criteria for statistical significance.

\section{Results}

The expression of miR-29a-3p in the five colorectal cancer cell lines. Multiple previous studies have shown that miR-29a-3p was overexpressed in CRC tissue $(3,18,19)$. In the present study, miR-29a-3p was detected in five human colorectal cancer cell lines, namely HCT116, Caco2, HT29, SW480 and SW620. The result of RT-qPCR showed that miR-29a-3p was detectable in all the five colorectal cancer cell lines (Fig. 1A).

Effects of miR-29a-3p inhibitor on viability of HCT116, SW480 and SW620. Transfection optimization indicated that three out of the five cell lines, SW480, SW620 and HCT116, were transfected successfully. Cell death siRNA acted as positive control in transfection optimization as cells which are successfully transfected will be killed. It was found that majority of SW480, SW620 and HCT116 cells were killed after transfection with cell death siRNA but no death was observed with HT29 and Caco2 (data not shown). Since miR-29a-3p was overexpressed in CRC, loss-of-function study using miR-29a-3p inhibitor was performed to determine the effect of miR-29a-3p inhibitor on viability of SW480, SW620 and HCT116. Cells were transfected with miR-29a-3p inhibitor or inhibitor control, and MTT assay was performed to detect cell viability after $96 \mathrm{~h}$. The average value of cell viability was divided by that of the corresponding negative control (inhibitor control) which was set as 1 . The data displayed in Fig. 2 show the means \pm SD obtained from 3 independent experiments. Statistical analysis was performed using one-sample t-test. The result demonstrated that miR-29a-3p inhibition had no significant effect on cell viability in the three cell lines $(\mathrm{P}>0.05)$.

Selection of invasive population of colorectal cancer cells in vitro. Since miR-29a-3p is overexpressed in CRC tissue according to the previous studies, it is implicated as an oncogene. To test the possible inhibitory effect of miR-29a-3p inhibitors on cell motility, invasive cells are required to perform invasion and migration assay. In order to evaluate the intrinsic invasive capability of the three CRC cell lines (HCT116, SW480 and SW620), Transwell invasion assay was performed without any treatment. Unfortunately, the invasive propensities of the three CRC cell lines were very poor and none of them achieved adequate invasion for the following quantification. For SW620 and HCT116, almost no cell could pass through the insert, whilst a few invaded SW480 cells were observed at the bottom of the insert. Therefore, an invasive subpopulation called SW480-7 was derived from SW480 cell line in vitro using the Transwell Matrigel invasion assay mentioned above. Cells that invaded to the bottom of the membrane were detached with $0.25 \%$ trypsin 

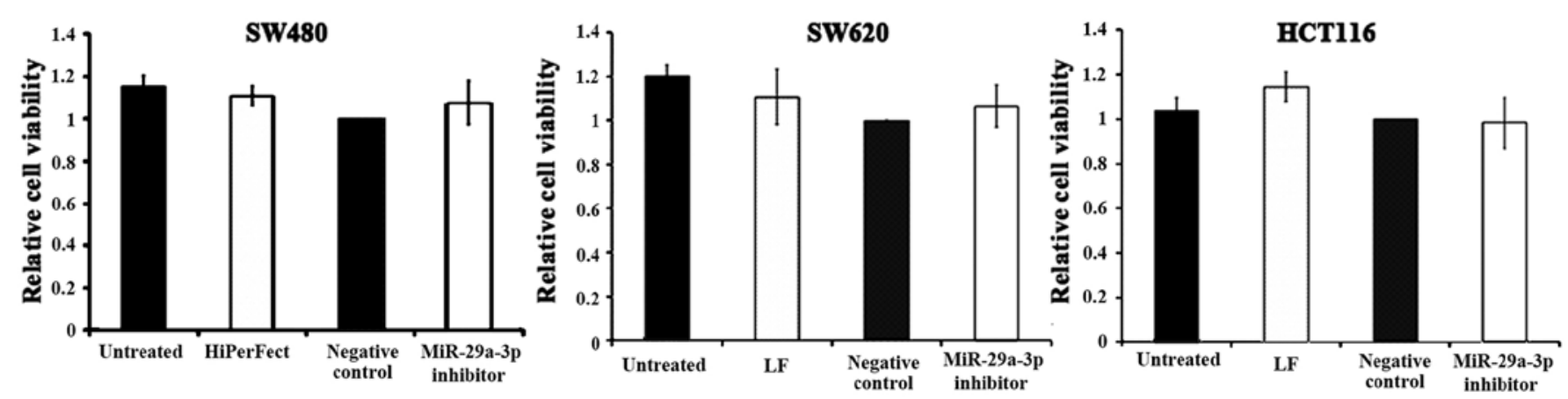

Figure 2. Effect of miR-29a-3p inhibitor on viability of SW480, SW620 and HCT116. Untreated, cells in culture medium only; LF, Lipofectamine 2000-treated cells; HF, HiPerFect-treated cells; negative control, transfection with miRNA inhibitor control; miR-29a-3p inhibitor, transfection with miR-29a-3p inhibitor.
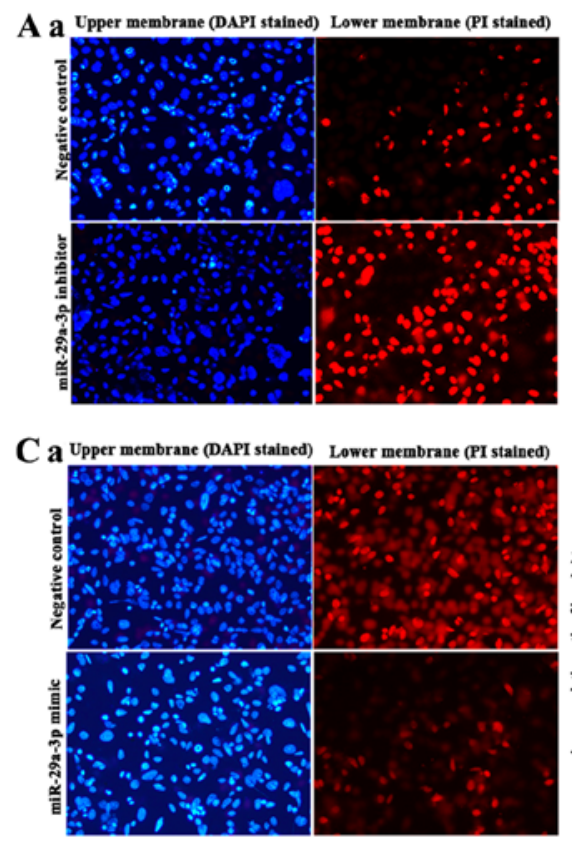
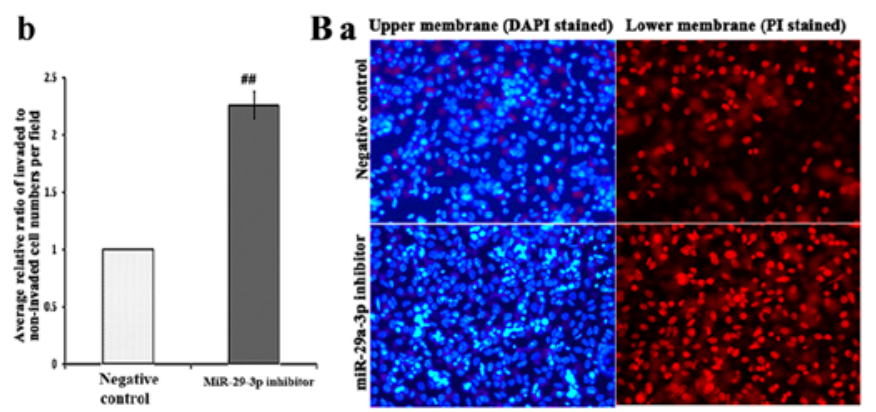

b

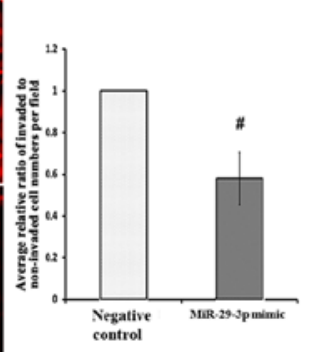

D a

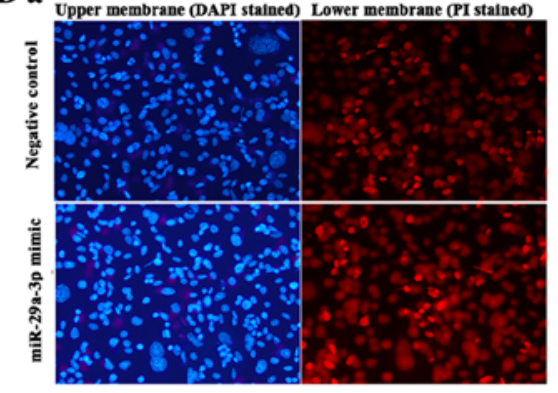

b

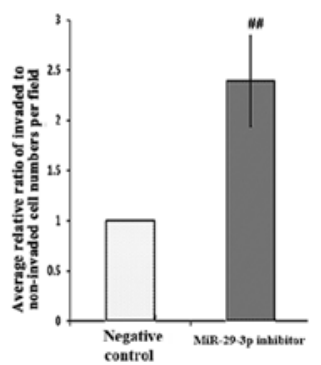

b

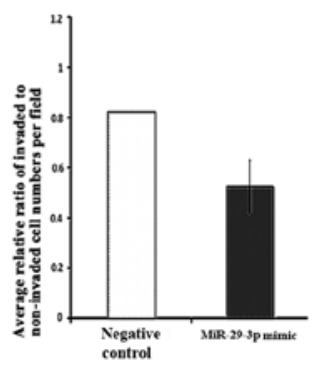

Figure 3. The effects of miR-29a-3p on cell invasion and migration. (A) Typical photographs of the invasion assay showing the role of miR-29a-3p inhibitor in invasion (a). The non-invaded cells were stained by DAPI (blue), and the cells invaded to the other side of the membrane were stained by PI (red). Quantification of invasion due to miR-29a-3p inhibition (b). (B) Typical photographs of the migration assay showing the role of miR-29a-3p inhibitor in migration (a). Quantification of migration due to miR-29a-3p inhibition (b). (C) Typical photographs of the invasion assay showing the role of miR-29a-3p mimic in invasion (a). Quantification of invasion due to miR-29a-3p overexpression (b). (D) Typical photographs of the migration assay showing the role of miR-29a-3p mimic in migration (a). Quantification of migration due to miR-29a-3p overexpression (b). ${ }^{\# \#} \mathrm{P}<0.01,{ }^{\#} \mathrm{P}<0.05$ vs negative control.

and cultured in a new cell culture flask filled with RPMI-1640 medium. An invasive subpopulation of SW480 called SW480-7 was established via 7 sequential passages through Matrigelcoated insert.

miR-29a-3p expression in SW480-7 cells. The invasive subpopulation, SW480-7, was established from the original SW480 cell line. To determine if the miR-29a-3p expression was altered in SW480-7 cells, real-time PCR was performed to assess miR-29a-3p in SW480 and SW480-7 cells (Fig. 1B). Unpaired t-test was employed to perform statistical analysis, and the results indicated that no significant difference was observed in miR-29a-3p expression between SW480 and SW480-7 cells $(10.3 \pm 1.14$ vs $12.9 \pm 1.57 ; \mathrm{P}=0.081)$.

Effects of miR-29a-3p on migration and invasion of SW480-7 cells. To further determine the effect of miR-29a-3p on cell motility, invasion assay and migration assay was carried out using Transwell assay. miR-29a-3p mimic and inhibitor were employed to perform gain-of-function and loss-of-function, respectively.

First, SW480-7 cells were transfected with miR-29a-3p inhibitor or negative control followed by cell invasion assay. The invasive capacity of the negative control group was used as the calibrator and set to 1 . Unexpectedly, the result showed there was a significant stimulation of cell invasion by the miR-29a-3p inhibitor $(2.3 \pm 0.12$, Fig. 3A). The subsequent cell migration assay showed that the miR-29a-3p inhibitor promoted cell migration (2.4 \pm 0.45 , Fig. 3B). Gain-of-function analyses using miR-29a-3p mimic were performed to further confirm the biological function of miR-29a-3p on cell migration and invasion. miR-29a-3p mimic or negative control was introduced into SW480-7 cells followed by Transwell cell invasion assay and migration assay. The results of gain-of-function 
Table III. Differentially expressed genes mediated by miR-29a-3p inhibitor.

\begin{tabular}{|c|c|c|c|}
\hline Symbol & Full name & Fold regulation & $\mathrm{Ct}$ value \\
\hline ARHGAP6 & Rho GTPase activating protein 6 & -2.6208 & 32.83 \\
\hline ARHGDIB & Rho GDP dissociation inhibitor (GDI) $\beta$ & -2.3784 & 28.48 \\
\hline AURKC & Aurora kinase $\mathrm{C}$ & -12.9063 & 34.38 \\
\hline CALD1 & Caldesmon 1 & 2.2501 & 20.71 \\
\hline CASK & Calcium/calmodulin-dependent serine protein kinase (MAGUK family) & -2.8284 & 24.43 \\
\hline CCNA1 & Cyclin A1 & 4.1125 & 29.95 \\
\hline CDC42BPA & CDC42 binding protein kinase $\alpha$ (DMPK-like) & 2.3295 & 20.4 \\
\hline CDC42EP2 & CDC42 effector protein (Rho GTPase binding) 2 & 2.6208 & 22.85 \\
\hline CDK5R1 & Cyclin-dependent kinase 5 , regulatory subunit $1(\mathrm{p} 35)$ & 2.2501 & 24.89 \\
\hline CLIP1 & CAP-GLY domain containing linker protein 1 & 2.042 & 17.4 \\
\hline CRK & V-crk sarcoma virus CT10 oncogene homolog (avian) & 2.1735 & 20.23 \\
\hline CTTN & Cortactin & 2.3457 & 22.58 \\
\hline EZR & Ezrin & 2.6027 & 19.04 \\
\hline IQGAP2 & IQ motif containing GTPase activating protein 2 & 10.9283 & 20.07 \\
\hline MAPT & Microtubule-associated protein $\tau$ & -2.2658 & 25.88 \\
\hline MID1 & Midline 1 (Opitz/BBB syndrome) & 2.1585 & 21.53 \\
\hline MSN & Moesin & -2.114 & 21.72 \\
\hline PAK1 & P21 protein (Cdc42/Rac)-activated kinase 1 & -4.1989 & 25.41 \\
\hline PHLDB2 & Pleckstrin homology-like domain, family B, member 2 & 3.9177 & 20.7 \\
\hline SSH1 & Slingshot homolog 1 (Drosophila) & 3.8906 & 23.61 \\
\hline $\mathrm{SSH} 2$ & Slingshot homolog 2 (Drosophila) & 2.5315 & 24.39 \\
\hline WAS & Wiskott-Aldrich syndrome (eczema-thrombocytopenia) & -3.5308 & 29.99 \\
\hline $\mathrm{B} 2 \mathrm{M}$ & $\beta$-2-microglobulin & 2.114 & 18.83 \\
\hline
\end{tabular}

$\mathrm{C}^{\mathrm{t},}$ cycle threshold.

study indicated that miR-29a-3p overexpression in SW480-7 cells suppressed cell invasion $(0.58 \pm 0.12)$ and migration $(0.64 \pm 0.13)$ significantly supports the observation of loss-offunction study (Fig. 3C and D).

Cytoskeleton Regulators $R T^{2}$ Profiler PCR array. To elucidate the underlying mechanism of alteration in migration caused by miR-29a-3p inhibition in vitro, Cytoskeleton Regulators $\mathrm{RT}^{2}$ Profiler PCR array was performed $48 \mathrm{~h}$ after transfection. The dynamic reorganization of cell cytoskeleton is an essential requirement of cell motility process. The expression of 84 cytoskeletal regulatory genes was analysed and multiple altered genes due to miR-29a-3p inhibition was revealed (Table III). Two filter conditions were applied to select target genes for further study. One is fold change and the other is cycle threshold $(\mathrm{Ct})$ value. The $\mathrm{Ct}$ value is inversely proportional to the amount of the gene detected in the sample, which means the higher the $\mathrm{Ct}$ level the lesser the amount of target gene. The genes regulated by a certain miRNA are divided into two general categories: direct targets and indirect targets. miRNA can suppress gene expression of direct targets through binding to the complementary sequence at 3' UTR, and the other genes at downstream are indirect targets. Three widely used databases, TargetScan (http://www.targetscan.org/), miRBD (http://mirdb.org/miRDB/) and DIANA (http://diana.imis. athena-innovation.gr/DianaTools/), were employed to identify

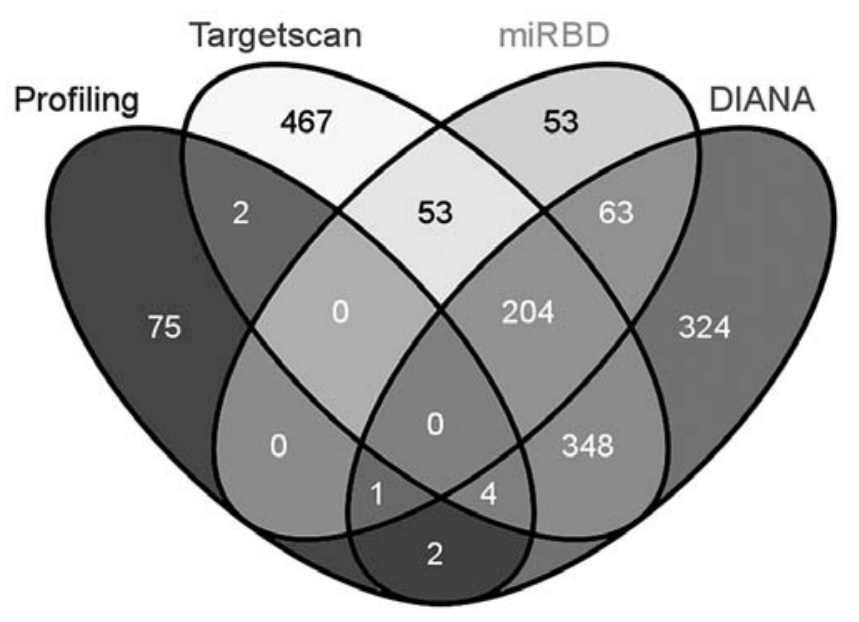

Figure 4. Intersection analysis of 84 -gene panel included in PCR array with potential direct targets of miR-29a-3p predicted by three widely used databases (TargetScan, miRBD and DIANA). Total numbers of genes for Profiling, TargetScan, miRBD, and DIANA were 84, 1078, 374, and 946, respectively. In the Venn diagram, the numbers inside intersections denote common genes of the corresponding sections, whereas the numbers outside intersections denote unique genes.

the potential direct target genes of miR-29a-3p in the 84-gene panel (Fig. 4). Five genes, namely CDC42, CDC42BPA, BAIAP2, MAPRE1 and TIAM1, were predicted as possible 
A

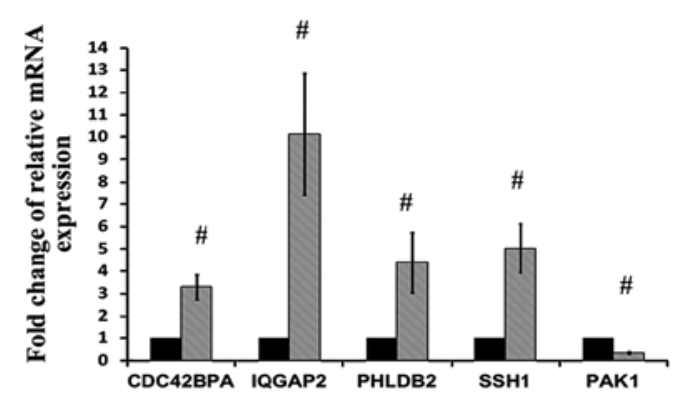

B

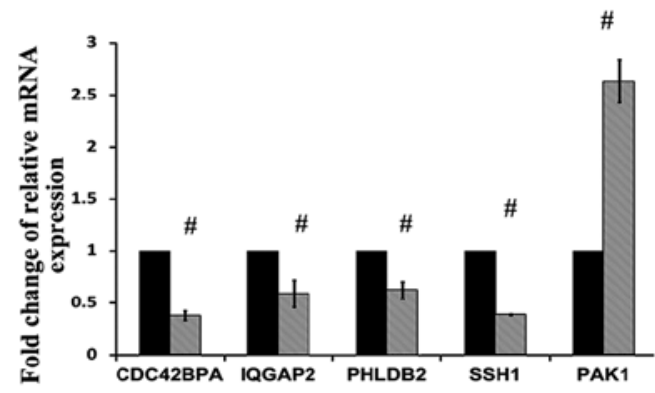

C

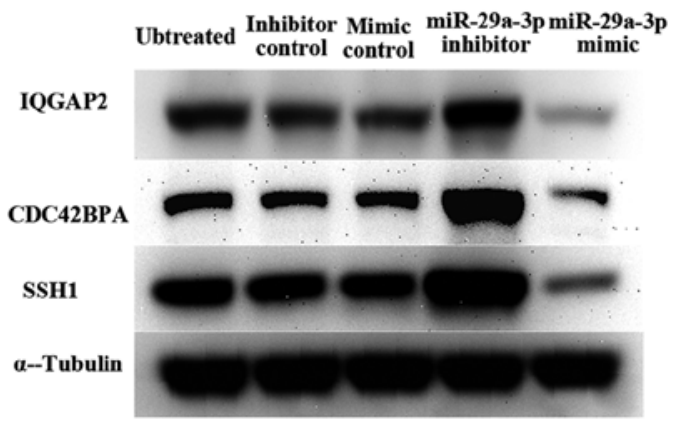

D
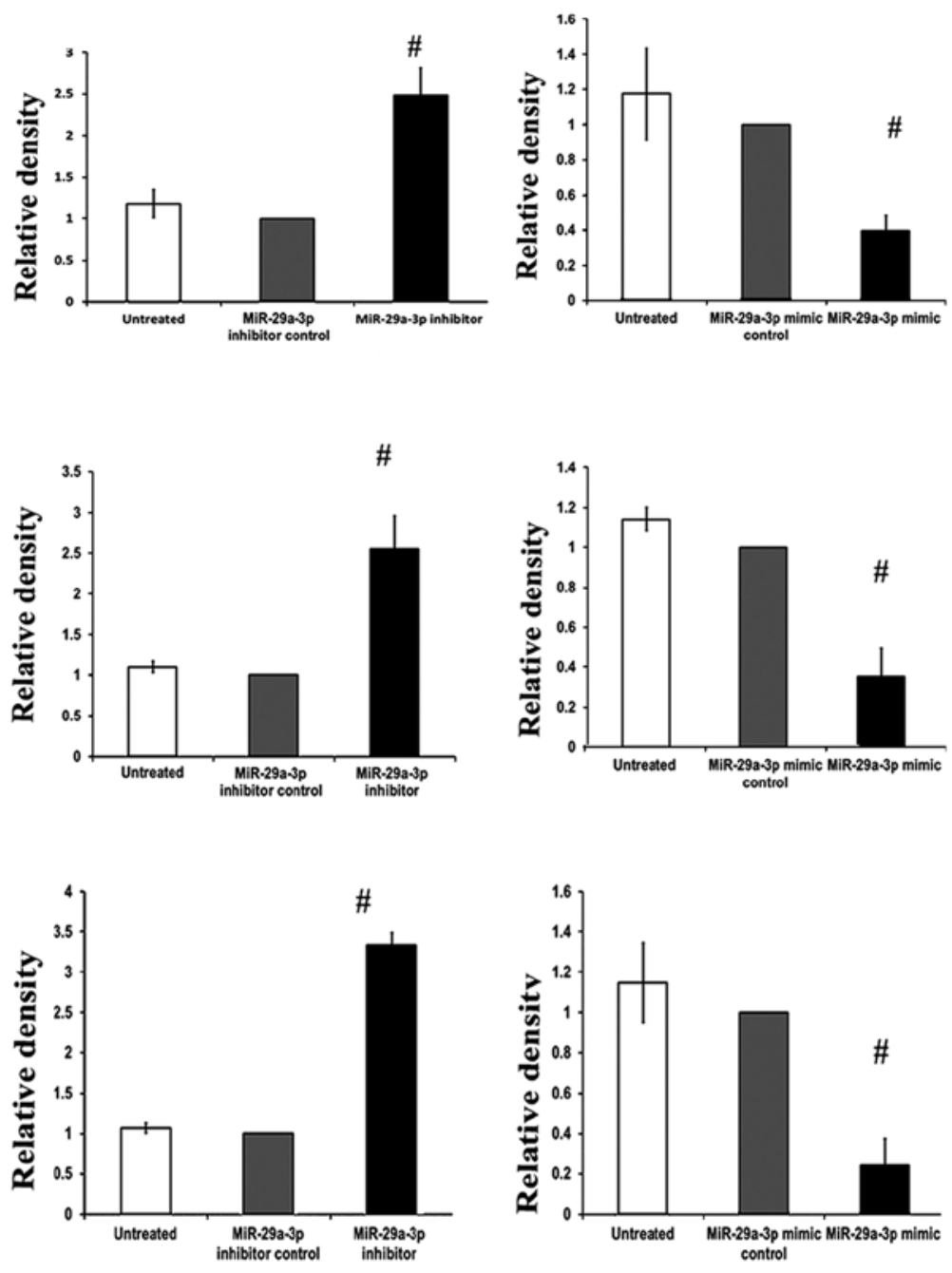

Figure 5. The effects of miR-29a-3p on mRNA and protein expression of several selected genes (CDC42BPA, IQGAP2, PHLDB2, SSH1 and PAK1) in SW480-7 cells. Effect of miR-29a-3p inhibitor and miR-29a-3p mimic on CDC42BPA, IQGAP2, PHLDB2, SSH1 and PAK1 mRNA expression was shown in (A) and (B), respectively. (C) Western blot analysis using specific antibodies against the corresponding cytoskeleton regulatory proteins was carried out and the immunoreactive bands are as shown. (D) Densitometric analysis using ImageJ was conducted to quantify the band intensities and the intensity values of $\alpha$-tubulin were used to normalize those of target proteins. Data represent means \pm SD from three independent experiments, and statistical analysis was done using one-sample t-test. The corresponding expression levels of control groups were used as calibrators (set to 1), and the statistical values compared to control group were displayed on the bar, respectively. CDC42BPA, CDC42 binding protein kinase $\alpha$ (DMPK-like); IQGAP2, IQ motif containing GTPase activating protein 2; PHLDB2, pleckstrin homology-like domain, family B, member 2; SSH1, slingshot homolog 1; PAK1, P21 protein (Cdc42/Rac)-activated kinase 1.

direct targets of miR-29a-3p by at least 2 databases, and the other seventy-nine genes were potential indirect targets. Since the interaction between a microRNA and the corresponding mRNAs has not been elucidated, all the predicted direct targets need to be verified experimentally. $\mathrm{RT}^{2}$ Profiler PCR array revealed that three out of the 5 genes were upregulated in SW480-7 cells transfected with miR-29a-3p inhibitor. These three mRNAs were CDC42BPA (2.33-fold), BAIAP2 (1.79-fold) and TIAM1 (1.77-fold). Since CDC42BPA was the gene with the largest-fold change of gene expression, it was selected as the representative predicted direct target for siRNA studies.

For the indirect targets of miR-29a-3p, the cut-off value for fold changes and the $\mathrm{Ct}$ value were set to 3.5 and 29, respectively. As a result, four genes, IQGAP2, PHLDB2, SSH1 and PAK1, fulfilled the inclusion criteria. Taken together, $\mathrm{RT}^{2}$ Profiler PCR array revealed that 5 genes, CDC42BPA, IQGAP2, PHLDB2, SSH1 and PAK1, were differentially expressed due to miR-29a-3p inhibition.

Confirmation of PCR array data at mRNA level. To further validate the accuracy and reproducibility of data from $\mathrm{RT}^{2}$ Profiler PCR array, qRT-PCR was repeated in three independent experiments to investigate the five selected genes (CDC42BPA, IQGAP2, PHLDB2, SSH1 and PAK1) and the results are summarized in Fig. 5A and B. Statistical analysis was done using one-sample t-test. The corresponding expression levels of control groups were used as calibrators which were set as one, and relative mRNA expression of each gene was compared to control group. In SW480-7 cells transfected with 
A

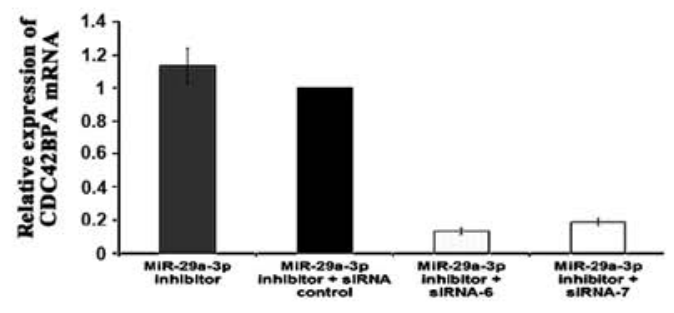

B

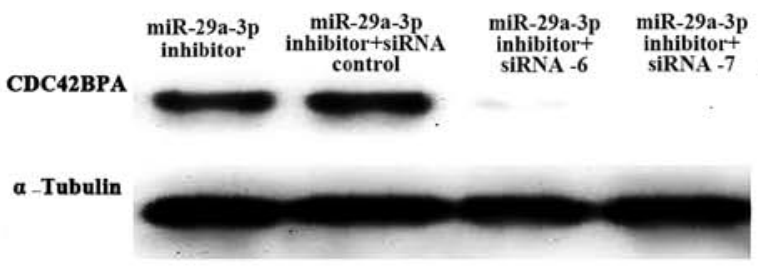

C

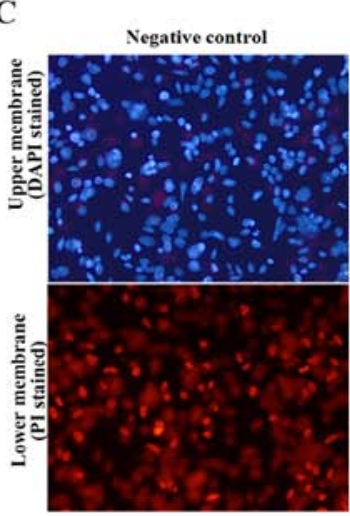

miR-29a-3p
inhibitor+siRNA control
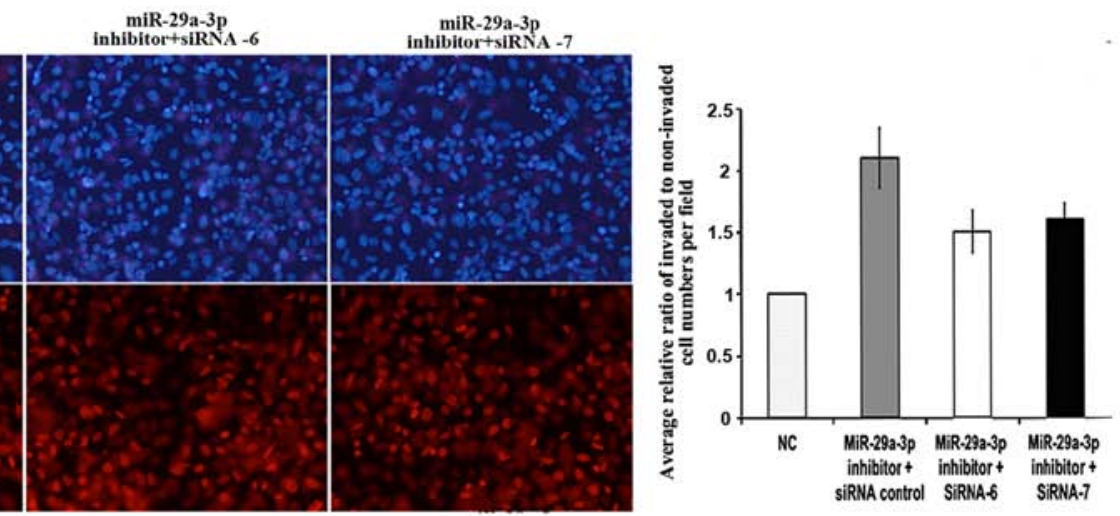

D
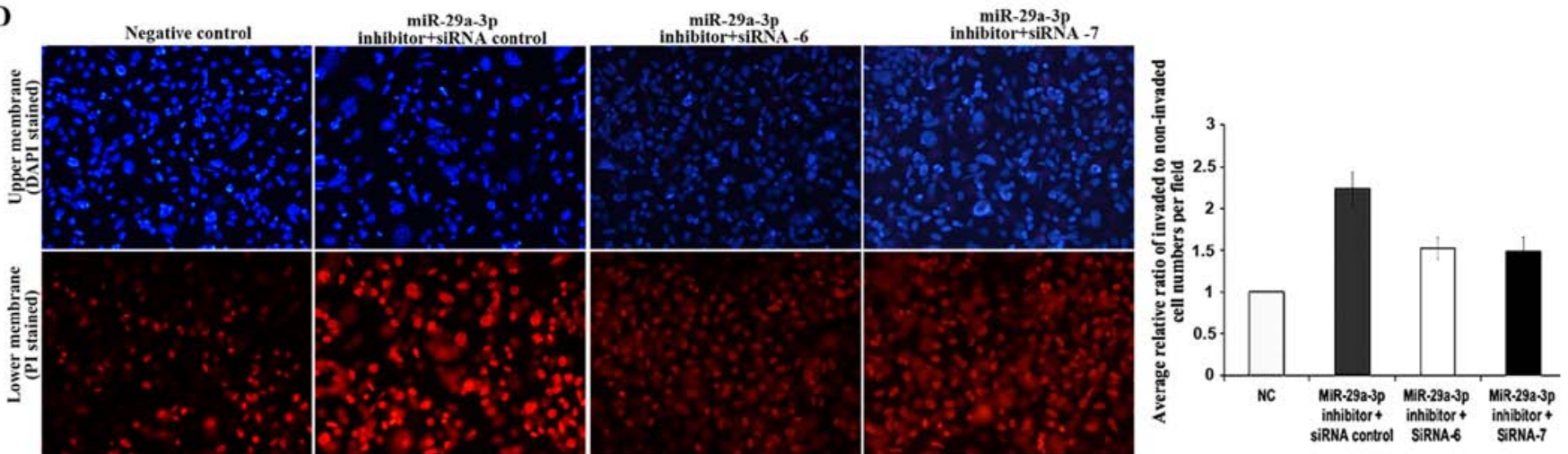

Figure 6. CDC42BPA knockdown in SW480-7 cells partially inhibits the miR-29a-3p inhibitor-induced stimulation of cell invasion and migration $96 \mathrm{~h}$ after transfection. (A) siRNA knockdown of CDC42BPA at mRNA level $48 \mathrm{~h}$ after transfection. Statistical analysis was done using one-sample t-test. (B) siRNA knockdown of CDC42BPA at protein level $72 \mathrm{~h}$ after transfection. (C) Effects of CDC42BPA on miR-29a-3p inhibitor-induced stimulation of cell invasion. (D) Effects of CDC42BPA on miR-29a-3p inhibitor-induced stimulation of cell migration. Statistical analysis between the experimental groups was conducted by one-way analysis of variance test. The statistical values were displayed on the bar, respectively. All the data represent means \pm SD of three independent experiments. The photographs under the bar chart represent the colorectal cancer cells in four random microscopic fields, the cells in upper membrane was stained by DAPI, and the cells in lower membrane was stained by PI.

miR-29a-3p inhibitor, mRNA expression levels of CDC42BPA, IQGAP2, PHLDB2 and SSH1 were increased to 3.3-, 10.1-, 4.4- and 5.0-fold, respectively, while the expression of PAK1 was reduced to 0.32 -fold significantly (Fig. 5A). Fig. 5B shows the effects of the miR-29a-3p mimic on the expression of CDC42BPA, IQGAP2, PHLDB2, SSH1 and PAK1 mRNAs in SW480-7 cells. In this study, miR-29a-3p mimic could reverse the role of $\mathrm{miR}-29 \mathrm{a}-3 \mathrm{p}$ inhibitor, decreased the expression of CDC42BPA (0.37-fold), IQGAP2 (0.58-fold), PHLDB2 (0.62-fold) and SSH1 (0.38-fold) mRNAs, and increased PAK1 (2.63) mRNA. The results of qRT-PCR in Fig. 5A and B were consistent with result from $\mathrm{RT}^{2}$ Profiler PCR array.

Measurement of alterations of protein expression by western blotting. The protein level is influenced by several factors apart from mRNA abundance. Thus, besides validating PCR array data at the mRNA level, it is also important to determine the protein levels. Three out of the five genes, CDC42BPA, IQGAP2 and SSH1 were selected for protein expression analysis due to the following reasons: i) CDC42BPA is the only potential direct target of miR-29a-3p. ii) IQGAP2 is the gene showed the largest-fold change and lowest $\mathrm{Ct}$ value (highest mRNA abundance). iii) Both polymerization and depolymerization of actin need to be activated to promote cell invasion and migration. SSH1 is the only gene related to depolymerization.

Cells were collected at $72 \mathrm{~h}$ after miR-29a-3p inhibitor and miR-29a-3p mimic transfection and the protein levels were assessed by western blot analysis (Fig. 5C). Statistical analysis was done using one-sample t-test and the corresponding P-values were shown in the bar charts (Fig. 5D). The western blot analysis results were consistent with the mRNA results. 
A

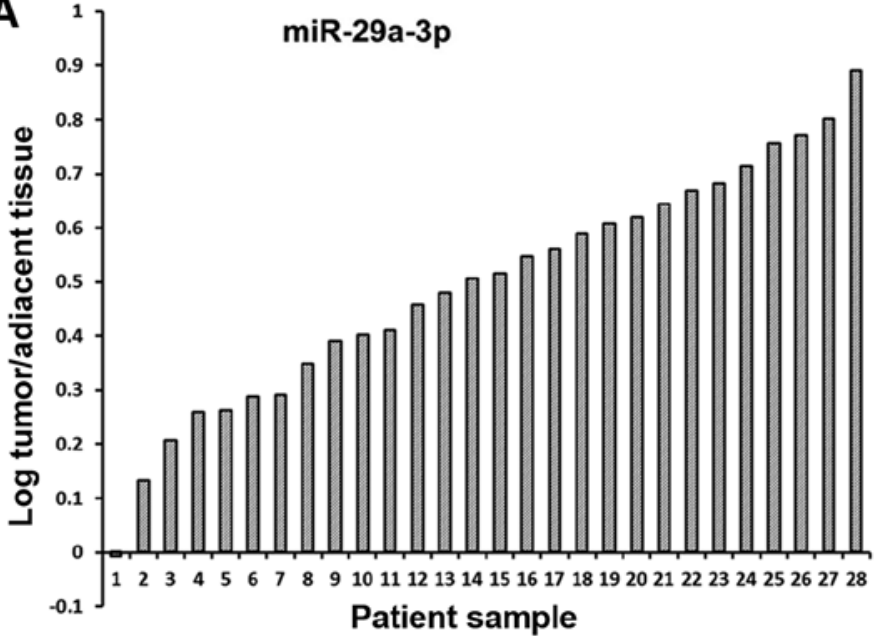

B

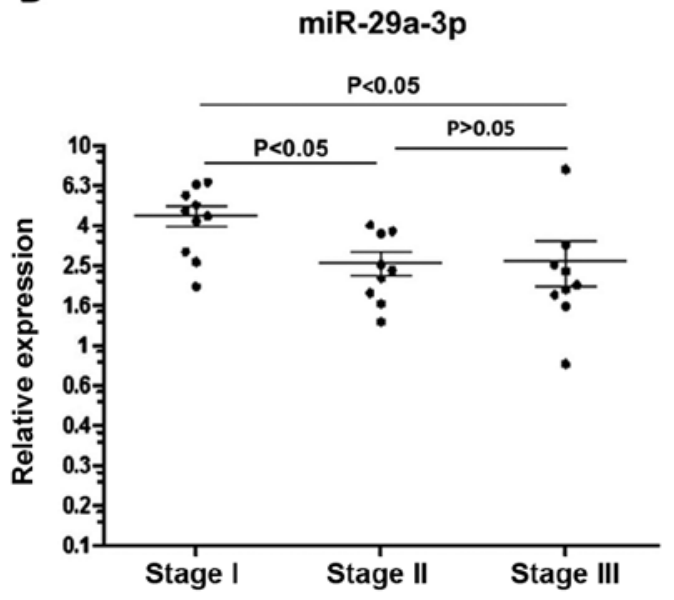

Figure 7. (A) Quantitative analysis of miR-29a-3p by RT-qPCR in twenty-eight colorectal cancer tumor tissues and the corresponding normal adjacent tissues. The mRNA level was expressed as log (tumor/relative adjacent tissue). Each bar represents an individual patient. (B) Differential expression of miR-29a-3p in three various colorectal cancer stages in 28 colorectal cancer patient tissues. The horizontal lines represent the mean value and standard deviation.

Transfection of miR-29a-3p inhibitor increased protein expression of CDC42BPA, IQGAP2, and SSH1, while miR-29a-3p mimic reduced protein expression of these three genes.

Effects of CDC42BPA on miR-29a-3p inhibitor-induced stimulation of cell migration and invasion. Small interfering RNA (siRNA) is a type of synthetic non-coding RNA (21-23 nucleotides) that inhibits gene expression by binding to a specific mRNA molecule (20). In recent years, siRNAs have been used to investigate single gene function. In the present study, two CDC42BPA-specific siRNAs, siRNA-6 and siRNA-7, were used to silence CDC42BPA. There were four groups: miR-29a-3p inhibitor group (group A) was transfected with miR-29a-3p inhibitor only; miR-29a-3p inhibitor + siRNA control group (group B) was cotransfected with miR-29a-3p inhibitor and siRNA control; miR-29a-3p inhibitor + siRNA-6 group (group C) was cotransfected with miR-29a-3p inhibitor and siRNA -6; miR-29a-3p inhibitor +siRNA-7 group (group D) was cotransfected with miR-29a-3p inhibitor and siRNA-7. RT-qPCR and western blot analyses were carried out to verify CDC42BPA silencing at mRNA level and protein level, respectively. The silencing of CDC42BPA mRNA expression induced by siRNA-6 and siRNA-7 was summarized in Fig. 6A. Statistical analysis was done using one-sample t-test. The CDC42BPA expression level of group B was used as calibrator which was set as 1 , and relative mRNA expression of other groups was compared to control group. As a result, mRNA expression levels of CDC42BPA were reduced significantly by siRNA-6 $(\mathrm{P}=0.0001)$ and siRNA-7 $(\mathrm{P}=0.0003)$. Both siRNA-6 and siRNA-7 were observed to induce silencing with greater than $80 \%$ efficiency. In accordance with the mRNA expression results, the western blot analysis results indicated that either siRNA-6 or siRNA-7 suppressed the protein expression of CDC42BPA (Fig. 6B).

To demonstrate the functional relevance of CDC42BPA in miR-29a-3p inhibitor-induced stimulation of cell invasion and migration, siRNA-6 and siRNA-7, were employed to silence CDC42BPA followed by cell invasion and migration assay. The results of cell invasion assay showed that cell invasion in siRNA control group was 2.11-fold higher than that of NC group, while siRNA-6 group and siRNA-7 group exhibited 1.49- and 1.61-fold higher cell invasion, respectively (Fig. 6C). The cell invasion capability of siRNA control group $(\mathrm{p}=0.0137)$, siRNA-6 group $(\mathrm{p}=0.0338)$ and siRNA-7 group $(\mathrm{p}=0.0131)$ were higher than that of $\mathrm{NC}$ group. However, the cell invasion capability of siRNA-6 group $(\mathrm{P}<0.05)$ and siRNA-7 group $(\mathrm{P}<0.05)$ was lower than that of siRNA control group. The results of migration assay indicated that cell migration of siRNA control group was 2.24-fold higher than that of NC group, while siRNA-6 group and siRNA-7 group exhibited 1.52- and 1.48-fold higher cell migration, respectively (Fig. 6D). The cell migration capability of siRNA control group, siRNA-6 group and siRNA-7 group were higher than that of NC group. However, the cell migration capability of siRNA-6 group and siRNA-7 group was lower than that of siRNA control group. Taken together, all the results suggested that CDC42BPA knockdown partially rescued the miR-29a-3p inhibitor-induced stimulation of cell invasion and migration in SW480-7 cells.

miR-29a-3p expression in colorectal cancer tissues and matched normal adjacent tissues. The expression of miR-29a-3p was assessed in 28 human colorectal cancer tissues and matched normal adjacent tissues (Fig. 7A). Of the 28 pairs of matched tissues, 27 pairs showed elevated expression of miR-29a-3p in tumor tissue. Statistical analysis was done using paired t-test. The paired comparison of miR-29a-3p expression between tumor tissues and normal adjacent tissues from the same patients showed a significant increase of miR-29a-3p expression in colorectal cancer tissues $(2.803 \pm 1.852$ vs $1.121 \pm 0.557 ; \mathrm{P}=0.0115)$.

miR-29a-3p expression in colorectal cancer tissues of various stages miR-29a-3p was detected in twenty-eight human CRC tissues. According to TNM staging system, these colorectal cancer samples can be divided into three subgroups: stage I consisting of 10 samples, stage II consisting of 9 samples, and stage III consisting of 9 samples. The expression pattern of 
miR-29a-3p in various stages is shown in Fig. 7B. One-way analysis of variance was used to compare means of three stages indicating that the highest level was found in stage I $(\mathrm{P}<0.05$ vs stage II; $\mathrm{P}<0.05$ vs stage III), while there was no significant difference between stage II and stage III $(\mathrm{P}>0.05)$. Furthermore, correlation between miRNA expression and colorectal cancer staging was analyzed using Spearman rank correlation test. The result indicated that there was negative correlation between miR-29a-3p expression and colorectal cancer staging $(\mathrm{P}=0.0032)$. However, the data need to be interpreted with caution due to the small sample size.

\section{Discussion}

Currently, the most widely used approaches to investigate the biological functions of miRNAs in cancer are phenotypic assays following loss-of-function and gain-of-function experiments. Loss-of-function experiments are always performed in conjunction with gain-of-function experiments to provide abundant evidence to establish the function of studied miRNAs. Loss-of-function experiments using miRNA inhibitor are best performed in cells that express the endogenous miRNAs at relatively high levels so that the alteration of target genes in response to miRNA inhibition can be obviously detected. Similarly, as miRNA mimics downregulate direct targets, gain-of-function experiments using miRNA mimics should be conducted in cells with low endogenous miRNAs and corresponding high target gene expression. The results of the present study showed that miR-29a-3p was detectable in all the five colorectal cancer cell lines, and SW480 was the cell line with moderate expression level of miR-29a-3p.

MTT assay was performed as a preliminary investigation to evaluate the effect of miR-29a-3p on the three cell growth-associated phenotypes. The results showed that neither miR-29a-3p inhibitor nor mimic had an effect on cell viability of the three colorectal cancer cell lines. Our result is in accordance with a previous study conducted by Tang et al which showed that miR-29a-3p has no influence on cell cycle regulation and cell proliferation in HCT116 cells (25). Several relevant studies also have been found regarding the effects of miR-29b-3p on cell viability of other kinds of cancers, including gastric cancer and oral squamous cell carcinoma. Lower levels of miR-29a-3p were detected in gastric cancer samples compared with normal adjacent tissue. A further functional study indicated that miR-29a-3p inhibits cell growth of gastric cancer in vitro (29). miR-29a-3p inhibitor or mimic was transfected into two oral squamous cell carcinoma, SCC-25 and SCC-9 cells, and the following MTT assay indicated that both mimic and inhibitor have no effect on the cell growth of the two cell lines within $96 \mathrm{~h}$ after transfection (15). The latter study is consistent with our data with the three colorectal cancer cell lines.

Abnormal cell growth and metastasis are regarded as the two major characteristics of cancer (30). Since miR-29a-3p had no effects on cell viability of the three selected colorectal cancer cell lines, further studies were carried out to investigate the effects of miR-29a-3p on cell invasion and migration which play an essential role in cancer metastasis. Relatively high invasive cell lines are required to show suppression of cell invasion due to miR-29a-3p inhibition. Unfortunately, the invasive properties of the three CRC cell lines were very poor and none of the three CRC cell lines achieved adequate invasion for quantification experiments. For SW620 and HCT116, almost no cells passed through the insert, whilst for SW480, a few cells invaded and were observed at the bottom of the insert. An invasive subpopulation called SW480-7 was then derived in vitro by subjecting SW480 parental cells to 7 sequential passages through Matrigel-coated $8.0-\mu \mathrm{m}$ pore polycarbonate membrane. This is a common method to gain an invasive subpopulation from established cancer cell lines by using Transwell inserts in vitro $(31,32)$. It is unclear why HCT116 used in the present study was not invasive. This differed from that by Tang et al (25). The difference may be due to the late passage of HCT116 used in this study.

Since published data have shown that miR-29a-3p is overexpressed in CRC tissue compared to normal adjacent tissue, knockdown of miR-29a-3p was hypothesized to inhibit cell invasion and migration. Unexpectedly, the results indicated that miR-29a-3p inhibition in SW480-7 cells stimulated cell invasion and migration. This could be attributed to alterations in the expression of some targets due to loss of miR-29a-3p expression resulting in increased cell migration and invasion. In order to elucidate the underlying mechanism contributing to cell migration and invasion, Cytoskeleton Regulators PCR array analysis was performed to identify the genes implicated in increased cell motility in miR-29a-3p-inhibitor transfected cells. Although majority of the published functional studies of miRs are focused on direct target determination, both direct targets and indirect targets are essential to exert full functional effects of miRs (33). Therefore, the present study was designed to elucidate the downstream changes in mRNAs by miRNA29a-3p inhibitor or mimic instead of identifying individual direct target which is usually carried out using the luciferase assay. In the present study, only the genes associated with cell migration and invasion were of interest and this was assessed by using the Cytoskeleton Regulator $\mathrm{RT}^{2}$ Profiler PCR array where expression levels of 84 cell cytoskeleton-associated mRNAs can be measured in response to the miR-29a-3p inhibitor. The dynamic reorganization of the cell cytoskeleton is an essential requirement for cell motility. Both polymerization and depolymerization of cell cytoskeleton are required to be maintained at a relatively high level to ensure a high speed of directional cell movement. Highest-fold change was observed with CDC42BPA and it was selected for siRNA experiments. The expression levels of four other mRNAs, IQGAP2, PHLDB2, SSH1 and PAK1 were most significantly altered in response to miR-29a-3p inhibition. The three widely used databases, TargetScan, miRBD and DIANA were used to predict the target genes of miR-29a-3p amongst the 84 mRNAs in the PCR array and identified CDC42BPA as the predicted target. This is consistent with a recent report showing CDC42BPA as a direct target gene of miR-29a in a luciferase assay (34). To further validate the accuracy and reproducibility of data from PCR array, another two independent experiments were performed to confirm the increased expression of CDC42BPA, IQGAP2, PHLDB2 and SSH1 mRNAs, and reduced expression of PAK1 mRNA by RT-qPCR. The results from the RT ${ }^{2}$ Profiler PCR array were consistent with the RT-qPCR data. As off-target effect is an unavoidable phenomenon in RNA interference experiments, a commonly used strategy to exclude 
possible off-target effects is to reverse the effect of miR-29a-3p inhibitor by increasing intracellular miR-29a-3p levels with the miR-29a-3p mimic. The miR-29a-3p mimic downregulated the expression of CDC42BPA, IQGAP2, PHLDB2 and SSH1 mRNAs and upregulated PAK1 mRNA expression. In conclusion, miR-29a-3p mimic can reverse the effect of miR-29a-3p inhibitor on expression of these five mRNAs which provides supporting evidence for the role of miR-29a-3p as a regulator of these five genes.

Besides mRNA abundance, protein levels are influenced by other factors such as mRNA stability and RNA-protein interactions (35). To confirm that alterations of CDC42BPA, IQGAP2 and SSH1 mRNA by miR-29a-3p also lead to changes in protein levels, western blotting was performed. Of these mRNAs, SSH1 is the only one involved in actin depolymerization, CDC42BPA is the only potential direct target of miR-29a-3p as predicted by TargetScan and DIANA and IQGAP2 showed the largest-fold change and highest mRNA abundance. Both western blot analysis and RT-qPCR results show increased levels CDC42BPA, IQGAP2, and SSH1 in miR-29a-3p inhibitor-transfected cells, while miR-29a-3p mimic reduced the level of these mRNAs and proteins. In most cases, a specific microRNA tends to decrease the target proteins to a moderate degree. A report by Selbach et al showed that changes in synthesis of protein in response to endogenous miRNA knockdown or miRNA transfection at a genome-wide scale were moderate and most changes were $<4$-fold (36). In the present study, the changes in protein expression were in the range of 2.4- to 4.2-fold which is in agreement with Selbach et al (36). Although CDC42BPA, SSH1 and IQGAP2 protein levels were increased by miR-29a-3p inhibitor, their functional relevance in increasing cell migration and invasion currently remains unclear. Actin dynamics, assembly of focal adhesions and contractility are three major factors that impact cell motility. SSH1 is shown to increase actin filaments disassembly through activating cofilin (37). It is demonstrated that IQGAP2 interacts with both active GTP-bound CDC42 and inactive GDP-bound CDC42 (38). CDC42BPA, a serine/ threonine-protein kinase is an important downstream effector of CDC42 and plays a role in the regulation of cytoskeleton reorganization and cell migration. It enhances cell motility through promoting contractile force generation and stress fibre formation (39). In addition, CDC42BPA enhances the connection between cell cytoskeleton to plasma membrane (40). Since CDC42BPA is highly correlated to cell motility, it is selected for further functional studies.

Both CDC42BPC siRNAs (siRNA-6 or siRNA-7) could knockdown CDC42BPA expression at both mRNA level and protein level resulting in partial reduction of miR-29a-3p inhibitor-induced stimulation of cell migration and invasion. This supports the role of CDC42BPA in reducing miR-29a-3pinduced cell migration and invasion but CDC42BPA silencing did not completely abolish the effects of miR-29a-3p inhibitor. Thus, this suggests that miR-29a-3p may also simultaneously modulate other genes to suppress cell migration and invasion. To the best of our knowledge, this is the first report showing that miR-29a-3p partially suppresses cell migration and invasion in colorectal cancer cells through targeting CDC42BPA. In contrast, a previous study reported that miR-29a-3p promoted invasion and metastasis of another colorectal cancer cell line, LoVo through targeting Kruppel-like factor 4 (KLF4) which is a tumor suppressor gene (25). Hence, depending on the cell line and miR-29 target, invasion and migration can be up- or downregulated.

Since miR-29a-3p level was higher in both serum and tissue of CRC patients with liver metastases than that in patients without metastasis, this suggests that miR-29a-3p is likely to act as an oncogene (7). Thus, we expected that the miR-29a-3p inhibitor would inhibit SW480-7 cell migration and invasion. Instead, we found that the inhibitor of miR-29a-3p enhanced SW480-7 cell migration and invasion whilst the mimic had the opposite effect. This appeared to contradict the oncogenic role of miR-29a-3p. However, similar findings have been reported with miR-145. As with miR-29a, higher expression of miR-145 was detected in CRC tissues in metastatic cases in comparison to those without metastasis suggesting that it was an oncogene (41). In vitro studies support the oncogenic role of miR-145, whereby, cell proliferation was promoted in SW620 cell line and migration and cell invasion was stimulated in HCT8 when miR-145 was overexpressed (41). Unexpectedly, miR-145 acted as a tumor suppressor in SW480 cell line when expression of miR-145 was enforced (42) and this is similar to our observation with the miR-29a-3p mimic. The studies by Akao et al (43) and Arndt et al (44) also demonstrated that miR-145 can exhibit opposite roles in different cell lines suggesting that the biological function of microRNAs depend on the cellular context. Arndt et al (44) suggested that the absence of oncogenic target genes and presence of unknown anti-proliferative targets may contribute to the oncogenic function of miR-145 in SW620 cells. Likewise, the presence of some unknown pro-migratory targets or absence of some anti-migratory targets, may be a possible explanation for the promotion of cell migration and invasion by miR-29a-3p inhibitor in SW480-7 cells. It should also be noted that miR-145 has also been found to be downregulated in CRC tissues compared with normal adjacent tissues $(23,43,44)$. The expression pattern of miR-145 in different subtypes of CRC tissue may be an explanation for the seemingly contradictory results on miR-145.

Our present study revealed that miR-29a-3p was detected in CRC tissues from three stages (stage I, stage II and stage III) and their corresponding normal adjacent tissues. In accordance with previous studies $(3,23,24)$, the present study showed that miR-29a-3p is overexpressed in CRC tissues as compared to the matched normal adjacent tissues. On further analysis, we found that miR-29a-3p expression in stage II and III is relatively lower than that of stage I. This observation is consistent with a previous clinical study showing the presence of miR-29a-3p in stage II CRC samples and high miR-29a expression was associated with longer disease-free survival (27). SW480, the cell line used in the present study, is a colorectal cancer cell line derived from a patient with stage II colorectal cancer (https://www.atcc.org/Products/ All/CCL-228.aspx\#generalinformation). At stage II, CRC has spread through the serosa to nearby organs displaying higher migration and invasion capacity compared to stage I CRC. Our data imply that the decrease in miR-29a-3p due to introduction of miR-29a-3p inhibitor may be responsible for the increased migration and invasion capacity of SW480-7. To the best of our knowledge, this is the first report showing miR-29a-3p 
expression pattern in three different stages in CRC. However, this result need to be interpreted with caution since the sample size of CRC tissue was small and further verification with increased sample size is required.

In conclusion, we found that miR-29a-3p was expressed in five colorectal cancer cell lines and is overexpressed in primary CRC tissues as compared to matched normal adjacent tissue. miR-29a-3p inhibitor had no effect on viability of colorectal cancer cell lines but stimulated cell migration and invasion of SW480-7 cells. In contrast, miR-29a-3p mimic decreased cell migration and invasion. The increased migration and invasion observed is likely due to increased expression of cytoskeletonassociated elements such as CDC42BPA, IQGAP2, PHLDB2, and SSH1. Silencing of CDC42BPA, a predicted direct target of miR-29a-3p, partially inhibited cell migration and invasion. These findings indicated that miR-29a-3p can potentially be useful for miRNA-based treatment of CRC patients.

\section{Acknowledgements}

The authors wish to thank the financial support of the Putra university under grant number GP-IPS/2014/943395 and the Malaysian Ministry of Science, Technology and Innovation under grant no. 02-01-04-SF1312. We would also like to express our appreciation to Samuel Leon Juan Khoo for helpful discussion on experimental techniques.

\section{References}

1. Torre LA, Bray F, Siegel RL, Ferlay J, Lortet-Tieulent J and Jemal A: Global cancer statistics, 2012. CA Cancer J Clin 65: 87-108, 2015.

2. Wightman B, Ha I and Ruvkun G: Posttranscriptional regulation of the heterochronic gene lin-14 by lin- 4 mediates temporal pattern formation in C. elegans. Cell 75: 855-862, 1993.

3. Motoyama K, Inoue H, Takatsuno Y, Tanaka F, Mimori K, Uetake H, Sugihara K and Mori M: Over- and under-expressed microRNAs in human colorectal cancer. Int $\mathbf{J}$ Oncol 34: 1069-1075, 2009.

4. Du Y, Wang L, Wu H, Zhang Y, Wang $\mathrm{K}$ and Wu D: MicroRNA-141 inhibits migration of gastric cancer by targeting zinc finger E-box-binding homeobox 2. Mol Med Rep 12: 3416-3422, 2015.

5. Kato M, Goto Y, Matsushita R, Kurozumi A, Fukumoto I, Nishikawa R, Sakamoto S, Enokida H, Nakagawa M, Ichikawa T, et al: MicroRNA-26a/b directly regulate La-related protein 1 and inhibit cancer cell invasion in prostate cancer. Int $\mathbf{J}$ Oncol 47: 710-718, 2015

6. Kawano M, Tanaka K, Itonaga I, Ikeda S, Iwasaki T and Tsumura H: microRNA-93 promotes cell proliferation via targeting of PTEN in osteosarcoma cells: J Exp Clin Cancer Res 34: 76, 2015.

7. Wang L-G and Gu J: Serum microRNA-29a is a promising novel marker for early detection of colorectal liver metastasis. Cancer Epidemiol 36: e61-e67, 2012.

8. Shukla K, Sharma AK, Ward A, Will R, Hielscher T, Balwierz A, Breunig C, Münstermann E, König R, Keklikoglou I, et al: MicroRNA-30c-2-3p negatively regulates NF- $\kappa \mathrm{B}$ signaling and cell cycle progression through downregulation of TRADD and CCNE1 in breast cancer. Mol Oncol 9: 1106-1119, 2015.

9. Wang Y, Zhang X, Li H, Yu J and Ren X: The role of miRNA-29 family in cancer. Eur J Cell Biol 92: 123-128, 2013.

10. Jiang H, Zhang G, Wu JH and Jiang CP: Diverse roles of miR-29 in cancer (review). Oncol Rep 31: 1509-1516, 2014.

11. Wang D, Qiu C, Zhang H, Wang J, Cui Q and Yin Y: Human microRNA oncogenes and tumor suppressors show significantly different biological patterns: From functions to targets. PLoS One 5: e13067, 2010.

12. Esquela-Kerscher A and Slack FJ: Oncomirs - microRNAs with a role in cancer. Nat Rev Cancer 6: 259-269, 2006.
13. Zhao Z, Wang L, Song W, Cui H, Chen G, Qiao F, Hu J, Zhou R and Fan H: Reduced miR-29a-3p expression is linked to the cell proliferation and cell migration in gastric cancer. World J Surg Oncol 13: 101, 2015.

14. Zhao D, Jiang X, Yao C, Zhang L, Liu H, Xia H and Wang Y: Heat shock protein 47 regulated by miR-29a to enhance glioma tumor growth and invasion. J Neurooncol 118: 39-47, 2014.

15. Lu L, Xue X, Lan J, Gao Y, Xiong Z, Zhang H, Jiang W, Song W and Zhi Q: MicroRNA-29a upregulates MMP2 in oral squamous cell carcinoma to promote cancer invasion and anti-apoptosis. Biomed Pharmacother 68: 13-19, 2014.

16. Yamamoto N, Kinoshita T, Nohata N, Yoshino H, Itesako T, Fujimura L, Mitsuhashi A, Usui H, Enokida H, Nakagawa M, et al: Tumor-suppressive microRNA-29a inhibits cancer cell migration and invasion via targeting HSP47 in cervical squamous cell carcinoma. Int J Oncol 43: 1855-1863, 2013.

17. Zhu XC, Dong QZ, Zhang XF, Deng B, Jia HL, Ye QH, Qin LX and $\mathrm{Wu} X Z$ : microRNA-29a suppresses cell proliferation by targeting SPARC in hepatocellular carcinoma. Int J Mol Med 30: 1321-1326, 2012.

18. Volinia S, Calin GA, Liu CG, Ambs S, Cimmino A, Petrocca F, Visone R, Iorio M, Roldo C, Ferracin M, et al: A microRNA expression signature of human solid tumors defines cancer gene targets. Proc Natl Acad Sci USA 103: 2257-2261, 2006.

19. Yanaihara N, Caplen N, Bowman E, Seike M, Kumamoto K, Yi M, Stephens RM, Okamoto A, Yokota J, Tanaka T, et al: Unique microRNA molecular profiles in lung cancer diagnosis and prognosis. Cancer Cell 9: 189-198, 2006.

20. Han YC, Park CY, Bhagat G, Zhang J, Wang Y, Fan JB, Liu M, Zou Y, Weissman IL and Gu H: microRNA-29a induces aberrant self-renewal capacity in hematopoietic progenitors, biased myeloid development, and acute myeloid leukemia. J Exp Med 207: 475-489, 2010.

21. Santanam U, Zanesi N, Efanov A, Costinean S, Palamarchuk A, Hagan JP, Volinia S, Alder H, Rassenti L, Kipps T, et al: Chronic lymphocytic leukemia modeled in mouse by targeted miR-29 expression. Proc Natl Acad Sci USA 107: 12210-12215, 2010.

22. Wu Q, Wang C, Lu Z, Guo L and Ge Q: Analysis of serum genome-wide microRNAs for breast cancer detection. Clin Chim Acta 413: 1058-1065, 2012.

23. Bandrés E1, Cubedo E, Agirre X, Malumbres R, Zárate R, Ramirez N, Abajo A, Navarro A, Moreno I, Monzó M, et al: Identification by Real-time PCR of 13 mature microRNAs differentially expressed in colorectal cancer and non-tumoral tissues. Mol Cancer 5: 29, 2006.

24. Kara M, Yumrutas O, Ozcan O, Celik OI, Bozgeyik E, Bozgeyik I and Tasdemir S: Differential expressions of cancer-associated genes and their regulatory miRNAs in colorectal carcinoma. Gene 567: 81-86, 2015.

25. Tang W, Zhu Y, Gao J, Fu J, Liu C, Liu Y, Song C, Zhu S, Leng Y, Wang G, et al: MicroRNA-29a promotes colorectal cancer metastasis by regulating matrix metalloproteinase 2 and E-cadherin via KLF4. Br J Cancer 110: 450-458, 2014.

26. Kuo TY, Hsi E, Yang IP, Tsai PC, Wang JY and Juo SH: Computational analysis of mRNA expression profiles identifies microRNA-29a/c as predictor of colorectal cancer early recurrence. PLoS One 7: e31587, 2012.

27. Weissmann-Brenner A, Kushnir M, Lithwick Yanai G, Aharonov R, Gibori H, Purim O, Kundel Y, Morgenstern S, Halperin M, Niv Y, et al: Tumor microRNA-29a expression and the risk of recurrence in stage II colon cancer. Int J Oncol 40: 2097-2103, 2012.

28. Yi R, Li Y, Wang FL, Miao G, Qi RM and Zhao YY: MicroRNAs as diagnostic and prognostic biomarkers in colorectal cancer. World J Gastrointest Oncol 8: 330-340, 2016.

29. Chen L, Xiao H, Wang ZH, Huang Y, Liu ZP, Ren H and Song H: miR-29a suppresses growth and invasion of gastric cancer cells in vitro by targeting VEGF-A. BMB Rep 47: 39-44, 2014.

30. Goubran HA, Kotb RR, Stakiw J, Emara ME and Burnouf T: Regulation of tumor growth and metastasis: The role of tumor microenvironment. Cancer Growth Metastasis 7: 9-18, 2014.

31. Chu YW, Yang PC, Yang SC, Shyu YC, Hendrix MJ, Wu R and Wu CW: Selection of invasive and metastatic subpopulations from a human lung adenocarcinoma cell line. Am J Respir Cell Mol Biol 17: 353-360, 1997.

32. Smith JJ, Deane NG, Wu F, Merchant NB, Zhang B, Jiang A, Lu P, Johnson JC, Schmidt C, Bailey CE, et al: Experimentally derived metastasis gene expression profile predicts recurrence and death in patients with colon cancer. Gastroenterology 138: 958-968, 2010. 
33. Alshalalfa M and Alhajj R: Using context-specific effect of miRNAs to identify functional associations between miRNAs and gene signatures. BMC Bioinformatics 14 (Suppl 12): S1, 2013.

34. Li S, Shen L, Sun L, Xu J, Jin P, Chen L and Ma F: Small RNA-Seq analysis reveals microRNA-regulation of the Imd pathway during Escherichia coli infection in Drosophila. Dev Comp Immunol 70: 80-87, 2017.

35. Blencowe B, Brenner S, Hughes $\mathrm{T}$ and Morris Q: Posttranscriptional gene regulation: RNA-protein interactions, RNA processing, mRNA stability and localization. Pac Symp Biocomput 14: 545-548, 2009.

36. Selbach M, Schwanhäusser B, Thierfelder N, Fang Z, Khanin R and Rajewsky N: Widespread changes in protein synthesis induced by microRNAs. Nature 455: 58-63, 2008.

37. Ohta Y, Kousaka K, Nagata-Ohashi K, Ohashi K, Muramoto A, Shima Y, Niwa R, Uemura T and Mizuno K: Differential activities, subcellular distribution and tissue expression patterns of three members of Slingshot family phosphatases that dephosphorylate cofilin. Genes Cells 8: 811-824, 2003.

38. Brill S, Li S, Lyman CW, Church DM, Wasmuth JJ, Weissbach L, Bernards A and Snijders AJ: The Ras GTPase-activating-proteinrelated human protein IQGAP2 harbors a potential actin binding domain and interacts with calmodulin and Rho family GTPases. Mol Cell Biol 16: 4869-4878, 1996.
39. Leung T, Chen XQ, Tan I, Manser E and Lim L: Myotonic dystrophy kinase-related Cdc42-binding kinase acts as a Cdc42 effector in promoting cytoskeletal reorganization. Mol Cell Biol 18: 130-140, 1998.

40. Nakamura N, Oshiro N, Fukata Y, Amano M, Fukata M, Kuroda S, Matsuura Y, Leung T, Lim L and Kaibuchi K: Phosphorylation of ERM proteins at filopodia induced by $\mathrm{Cdc} 42$. Genes Cells 5: 571-581, 2000.

41. Kamatani A, Nakagawa Y, Akao Y, Maruyama N, Nagasaka M, Shibata T, Tahara T and Hirata I: Downregulation of antioncomirs miR-143/145 cluster occurs before APC gene aberration in the development of colorectal tumors. Med Mol Morphol 46: 166-171, 2013.

42. Slaby O, Svoboda M, Fabian P, Smerdova T, Knoflickova D, Bednarikova M, Nenutil R and Vyzula R: Altered expression of miR-21, miR-31, miR-143 and miR-145 is related to clinicopathologic features of colorectal cancer. Oncology 72: 397-402, 2007.

43. Akao Y, Nakagawa Y and Naoe T: MicroRNAs 143 and 145 are possible common onco-microRNAs in human cancers. Oncol Rep 16: 845-850, 2006.

44. Arndt GM1, Dossey L, Cullen LM, Lai A, Druker R, Eisbacher M, Zhang C, Tran N, Fan H, Retzlaff K, et al: Characterization of global microRNA expression reveals oncogenic potential of miR-145 in metastatic colorectal cancer. BMC Cancer 9: 374, 2009. 